\title{
P-Wave Dispersion and Atrial Electromechanical Delay in Patients with Preeclampsia
}

\author{
Sinan Incia Gökay Nar ${ }^{a}$ Gökhan Aksan ${ }^{c}$ Haydar Sipahioğlu ${ }^{b}$ Korhan Soylu ${ }^{d}$ \\ Ali Dogan \\ Departments of a Cardiology and ${ }^{b}$ Obstetrics, Aksaray State Hospital, Aksaray, ${ }^{\mathrm{c} D e p a r t m e n t}$ of Cardiology, \\ Gazi State Hospital, and d Department of Cardiology, Faculty of Medicine, Ondokuz Mayis University, Samsun, and \\ e Department of Cardiology, Faculty of Medicine, Erciyes University, Kayseri, Turkey
}

\section{Key Words}

Atrial electromechanical delay · Intra-atrial conduction time . Interatrial conduction time · Preeclampsia · Tissue Doppler imaging

\begin{abstract}
Objectives: To investigate the duration of atrial electromechanical delay (EMD) and left atrial mechanical function in patients with preeclampsia. Materials and Methods: This study included 26 pregnant women with preeclampsia and 24 age-matched pregnant women without preeclampsia (control group). Atrial electromechanical coupling (PA) and intra-atrial and interatrial EMD were measured using tissue Doppler echocardiography. P-wave dispersion (PWD) was measured via 12-lead electrocardiography. All data were analyzed using SPSS v.15.0 for Windows (SPSS, Inc., Chicago, III., USA). Differences in continuous variables between groups were examined using a nonparametric Mann-Whitney $U$ test. Correlation analysis was performed using Spearman's coefficient of correlation. Categorical values were compared using a $x^{2}$ test. Results: PA lateral and PA septal durations were significantly longer in the preeclampsia group than in the control group $[74.6 \pm 8.1 \mathrm{vs} .62 .3 \pm 5.3 \mathrm{~ms}(p<0.001)$ and $59.7 \pm 5.3$ vs. $56.2 \pm 4.9 \mathrm{~ms}(p=0.005)$, respectively]. The duration of interatrial EMD and intra-atrial EMD in the pre-
\end{abstract}

eclampsia group was significantly longer than in the control group $[25.4 \pm 4.6$ vs. $13.2 \pm 3.9 \mathrm{~ms}(p<0.001)$ and $10.5 \pm 1.9$ vs. $7.1 \pm 1.2 \mathrm{~ms}(\mathrm{p}<0.001)$, respectively]. PWD was significantly higher in patients with preeclampsia $(43.1 \pm 9.1 \mathrm{~ms})$ than in the controls ( $37.6 \pm 7.9 \mathrm{~ms} ; \mathrm{p}=0.008)$. There was a significant correlation between PWD and interatrial EMD and intra-atrial EMD $[r=0.46(p<0.001)$ and $r=0.39(p<$ 0.001 ), respectively]. Conclusion: The duration of atrial EMD and PWD was prolonged in patients with preeclampsia.

(c) 2015 S. Karger AG, Basel

\section{Introduction}

Preeclampsia occurs in $2-8 \%$ of all pregnancies, and it is the leading cause of maternal and perinatal morbidity and mortality [1]. This multisystem disorder can occur after mid-gestation. It occurs in both nulliparous and multiparous women, and it is characterized by new-onset hypertension and proteinuria [2]. Hypertension is a key feature of preeclampsia which usually resolves within 3 months of delivery, but the associated risks are not always resolved [2].

The size of the enlarged left atrium (LA) is the most commonly used parameter for estimating the degree of atrial remodeling [3-6]. In addition to LA volume and

\begin{tabular}{ll}
\hline KARGER 125:s & $\begin{array}{l}\text { () 2015 S. Karger AG, Basel } \\
1011-7571 / 15 / 0246-0515 \$ 39.50 / 0 \quad \text { Karger }\end{array}$ \\
$\begin{array}{l}\text { E-Mail karger@karger.com } \\
\text { www.karger.com/mpp }\end{array}$ & $\begin{array}{l}\text { This is an Open Access article licensed under the terms of the } \\
\text { Creative Commons Attribution-NonCommercial 3.0 Un- } \\
\text { ported license (CC BY-NC) (www.karger.com/OA-license), } \\
\text { applicable to the online version of the article only. Distribu- } \\
\text { tion permitted for non-commercial purposes only. }\end{array}$
\end{tabular}

Sinan İnci, MD

Aksaray State Hospital

Zafer Mah., Nevșehir Cad. No: 117

TR-68100 Aksaray (Turkey)

E-Mail doktorsinaninci@gmail.com 
mechanical function, interatrial and intra-atrial conduction delay are also used. The atrial conduction time is important because it indicates LA electrical and structural remodeling [3]. P-wave dispersion (PWD) is an electrocardiographic (ECG) marker associated with a nonhomogeneous and discontinuous distribution of the sinus impulse [7]. In addition, PWD is accepted as a marker of prolonged interatrial and intra-atrial conduction times [8]. It has been reported that a prolonged PWD is an independent risk factor for the development of atrial fibrillation (AF) [7]. Although the atrial conduction time is indicative of the degree of atrial electrical remodeling, tissue Doppler echocardiography and 2 simple ECG markers - maximum P-wave duration (Pmax) and PWD could provide information about prolongation of the atrial conduction time [7-9].

Prolonged interatrial and intra-atrial conduction times have been reported in chronic prehypertension [3] and systemic hypertension [4]; however, the effect of acute pressure overload on the atrial conduction time in women with preeclampsia remains unknown. Preeclampsia is a natural condition of acute pressure overload [2]. The aim of the present study was to determine the effect of short-term pressure overload, such as that which affects LA mechanical function, and atrial conduction time in women with preeclampsia.

\section{Subjects and Methods}

\section{Study Population}

This study included 26 pregnant women with placental type preeclampsia (preeclampsia group) and 24 age-matched pregnant women without preeclampsia (control group). Preeclampsia was diagnosed using the criteria of the International Society for the Study of Hypertension in Pregnancy [10]. Therefore, in this study, preeclampsia was defined as: diastolic blood pressure $\geq 110 \mathrm{~mm}$ $\mathrm{Hg}$ on 1 occasion or diastolic blood pressure $\geq 90 \mathrm{~mm} \mathrm{Hg}$ on 2 consecutive occasions $>4 \mathrm{~h}$ apart, in combination with proteinuria (300 mg total protein in 24-hour urine collection or, if this was not available, $\geq 2$ proteinuria by dipstick analysis on 2 consecutive occasions $\geq 4$ h apart) that developed after the 20th week of gestation in previously normotensive women.

The subjects were then classified as appropriate for gestational age (AGA), small for gestational age (SGA), or large for gestational age (LGA) based on their weight for gestational age. SGA was defined as a weight below the 10th percentile for gestational age, AGA was defined as a weight between the 10th and the 90th percentiles, and LGA was defined as a weight above the 90 th percentile for gestational age.

Each participant provided written informed consent, and the study protocol was approved by the Institutional Ethics Committee. Exclusion criteria were: preeclampsia superimposed on chronic hypertension, a history of preeclampsia, significant valvular heart disease, atrial flutter or fibrillation, frequent ventricular preexcitation and atrioventricular conduction abnormality, renal failure, heart failure, pericarditis, collagen vascular disease, thyroid dysfunction, hypercholesterolemia, electrolyte imbalance, pulmonary disease, a technically insufficient echocardiographic image, and an ECG in which the start or end of the P-wave could not be clearly discerned.

\section{PWD Measurement via a 12-Lead ECG}

Following 10 min of rest, each participant underwent a 12-lead ECG in the supine position, conducted at a rate of $50 \mathrm{~mm} \cdot \mathrm{s}^{-1}$ with an amplitude of $20 \mathrm{~mm} \cdot \mathrm{mV}^{-1}$. ECG were manually measured using a magnifying glass by 2 cardiologists who were blinded to the clinical status of the patients. The starting point of the first positive wave moving in an upward direction or the first negative wave moving in a downward direction that could be observed from the isoelectric line was considered the origin of the P-wave. The turning point of the wave toward the isoelectric line was considered the end of the P-wave. PWD was calculated based on measurement of the longest (Pmax) and shortest (Pmin) P-waves in any lead of the 12-lead ECG [11] (PWD = Pmax - Pmin). The intra- and interobserver coefficients of variation (SD of the differences between 2 observations were divided by the mean value and expressed as percentages) were 4.5 and $3.2 \%$ for PWD.

\section{Standard Echocardiography}

Echocardiographic examination of the patients in both groups was performed in the left decubitus position using a GE Vingmed Vivid 5 echocardiography device (GE Vingmed Ultrasound, Horten, Norway). All measurements were performed by 2 cardiologists (S.I. and G.N.) experienced in echocardiography who were blinded to the clinical status of the patients. During the echocardiographic evaluation, a 1-lead echocardiography was recorded. Parasternal long-axis, short-axis, and apical 4-chamber and 2-chamber images were obtained and evaluated using M-mode, 2-D, continuous wave Doppler, pulse wave Doppler, and tissue Doppler methods according to American Echocardiography Society criteria. The cardiac output was calculated using measurements obtained from the left ventricular (LV) outflow tract diameter (cross-sectional area), the Doppler-derived velocity time integral of the LV outflow tract, and the heart rate. The LV outflow tract diameter measurement was taken using the parasternal longaxis view, and the LV outflow tract velocity time integral was obtained from the apical 4-chamber view [12]. Values were measured for 3 separate beats and then averaged for all parameters.

\section{Assessment of LA Mechanical Function}

The LA volume was determined based on apical 4-chamber views [13], and the LA maximum volume (Vmax) at the end-systolic phase, the LA minimum volume (Vmin) at the end-diastolic phase, and the LA volume before atrial systole $(\mathrm{Vp})$ (origin of the P-wave via ECG) were measured and calculated, indexed to the body surface area. Parameters of LA function were calculated as follows:

LA passive emptying volume $=\mathrm{Vmax}-\mathrm{Vp}$

LA passive emptying fraction $=[(\mathrm{V} \max -\mathrm{Vp}) / \mathrm{Vmax}] \cdot 100 \%$

LA active emptying volume $=\mathrm{Vp}-\mathrm{Vmin}$

$\mathrm{LA}$ active emptying fraction $=[(\mathrm{Vp}-\mathrm{Vmin}) / \mathrm{Vp}] \cdot 100 \%$

LA total emptying volume $=\mathrm{V} \max -\mathrm{V} \min$

LA ejection fraction $=[(\mathrm{V} \max -\mathrm{Vmin}) / \mathrm{V} \max ] \cdot 100 \%[14]$. 
Table 1. Baseline clinical and laboratory characteristics

\begin{tabular}{|c|c|c|c|}
\hline & $\begin{array}{l}\text { Preeclampsia group } \\
(\mathrm{n}=36)\end{array}$ & $\begin{array}{l}\text { Control group } \\
(\mathrm{n}=34)\end{array}$ & $\mathrm{p}$ value \\
\hline Age, years & $30.1 \pm 5.7$ & $29.3 \pm 3.6$ & 0.432 \\
\hline Nulliparous, n (\%) & $26(72)$ & $21(61)$ & 0.863 \\
\hline Multiparous, n (\%) & $10(28)$ & $13(39)$ & 0.755 \\
\hline Gestational age, weeks & $35.9 \pm 1.4$ & $38.1 \pm 0.8$ & $<0.001$ \\
\hline Preeclampsia duration at cardiac assessment, weeks & $9.7 \pm 2.5$ & & \\
\hline Mean birth weight, $g$ & $2,985 \pm 224$ & $3,467 \pm 435$ & $<0.001$ \\
\hline SGA, n (\%) & $16(44.4)$ & $2(5.9)$ & $<0.001$ \\
\hline AGA, n (\%) & $18(55.6)$ & $29(85.3)$ & $<0.001$ \\
\hline LGA, n (\%) & 0 & $3(8.8)$ & $<0.001$ \\
\hline $\mathrm{BMI}$ & $28.6 \pm 5$ & $27.1 \pm 3.9$ & 0.090 \\
\hline Smoking, n (\%) & $9(25)$ & $8(24)$ & 0.825 \\
\hline Systolic blood pressure, $\mathrm{mm} \mathrm{Hg}$ & $164.4 \pm 4.8$ & $116.3 \pm 14.3$ & $<0.001$ \\
\hline Diastolic blood pressure, $\mathrm{mm} \mathrm{Hg}$ & $105.4 \pm 4.2$ & $72.3 \pm 13.1$ & $<0.001$ \\
\hline Heart rate, bpm & $88.3 \pm 10$ & $85.6 \pm 10$ & 0.258 \\
\hline Creatinine, $\mathrm{mg} \cdot \mathrm{dl}^{-1}$ & $0.82 \pm 0.1$ & $0.78 \pm 0.1$ & 0.422 \\
\hline Serum glucose, $\mathrm{mg} \cdot \mathrm{dl}^{-1}$ & $86.2 \pm 10.4$ & $87.7 \pm 10.9$ & 0.571 \\
\hline Triglyceride, $\mathrm{mg} \cdot \mathrm{dl}^{-1}$ & $157.2 \pm 47.2$ & $148.4 \pm 57.4$ & 0.445 \\
\hline Low-density lipoprotein cholesterol, $\mathrm{mg} \cdot \mathrm{dl}^{-1}$ & $125.0 \pm 37$ & $134.2 \pm 36.9$ & 0.283 \\
\hline High-density lipoprotein cholesterol, $\mathrm{mg} \cdot \mathrm{dl}^{-1}$ & $48.4 \pm 9.3$ & $51.3 \pm 9.8$ & 0.436 \\
\hline Total cholesterol, $\mathrm{mg} \cdot \mathrm{dl}^{-1}$ & $202.6 \pm 38.7$ & $212.4 \pm 36.8$ & 0.484 \\
\hline Hemoglobin, $\mathrm{g} \cdot \mathrm{dl}^{-1}$ & $12.2 \pm 1.6$ & $12.4 \pm 2.0$ & 0.122 \\
\hline White blood cell count, $\mathrm{n} \cdot 10^{3} \cdot \mathrm{mm}^{-3}$ & $7.27 \pm 1.56$ & $7.56 \pm 1.87$ & 0.382 \\
\hline Platelets, $\mathrm{n} \cdot 10^{3} \cdot \mathrm{mm}^{-3}$ & $155.2 \pm 51.8$ & $188.4 \pm 58.5$ & 0.286 \\
\hline
\end{tabular}

\section{Interatrial and Intra-Atrial Electromechanical Delay}

All electromechanical delay (EMD) times used to measure interatrial and intra-atrial EMD were determined using tissue Doppler imaging and concurrent ECG rhythm traces. Atrial systole was considered as the A-wave (A) that was the second negative deviation at diastole in the tissue Doppler trace. The time from the onset of the P-wave on the surface ECG and the delayed diastolic wave (A) on tissue Doppler was considered PA, whereas measurements were obtained from the lateral mitral annulus (PA lateral), the septal annulus (PA septal), and the LV tricuspid annulus (PA tricuspid) on an apical 4-chamber image in a manner in which the 5 cardiac cycles were averaged [15]. Interatrial and intra-atrial EMD were calculated as follows [16]: the interatrial EMD is the difference in time between PA lateral and PA tricuspid, while the intra-atrial EMD is the difference in time between PA septal and PA tricuspid.

All measurements were performed by 2 experienced investigators (S.İ. and G.N.) blinded to the clinical status of the patients. The reproducibility of electromechanical parameters was assessed based on coefficients of variation (SD of the differences between the repeated measurements divided by the mean value and then expressed as a percentage) between measurements. Intraobserver variability was calculated based on 50 randomly selected patients (26 from the preeclampsia group and 24 from the control group) by repeating the measurements under identical basal conditions. Intraobserver variability was $3.2 \%$ for PA lateral, $3.3 \%$ for PA septal, and $3.1 \%$ for PA tricuspid. The interobserver variability was $4.7 \%$ for PA lateral, $4.6 \%$ for PA septal, and $4.7 \%$ for PA tricuspid.

\section{Statistical Analysis}

All data were analyzed using SPSS v.15.0 for Windows (SPSS, Inc., Chicago, Ill., USA). Categorical variables are presented as frequencies and percentages, and continuous variables are expressed as means \pm SD. The normality of the distribution of continuous variables was tested using the Kolmogorov-Smirnov test. Differences in continuous variables between groups were examined using the nonparametric Mann-Whitney U test. Correlation analysis was performed using Spearman's coefficient of correlation. Categorical values were compared using a $\chi^{2}$ test. $\mathrm{p}<0.05$ was considered statistically significant.

\section{Results}

Clinical and laboratory findings are shown in table 1. There were no significant differences in age, BMI, heart rate, lipid parameters, creatinine, glucose, white blood cell counts, hemoglobin, or thrombocyte values between the groups $(p>0.05)$. Systolic and diastolic blood pressures were significantly higher and gestational age was significantly lower in the preeclampsia group. Based on conventional echocardiographic measurements, there were no significant differences in ventricular septal thickness, posterior wall thickness, LV end-diastolic dimen- 
Table 2. Conventional echocardiographic parameters

\begin{tabular}{lccr}
\hline & $\begin{array}{l}\text { Preeclampsia } \\
\text { group } \\
(\mathrm{n}=36)\end{array}$ & $\begin{array}{l}\text { Control } \\
\text { group } \\
(\mathrm{n}=34)\end{array}$ & p value \\
\hline IVS thickness, mm & $9.5 \pm 1.5$ & $8.9 \pm 1.5$ & 0.214 \\
PW thickness, mm & $9.2 \pm 1.2$ & $8.6 \pm 1.5$ & 0.355 \\
LVEDD, mm & $46.2 \pm 4.5$ & $45.8 \pm 3.8$ & 0.757 \\
LVESD, mm & $29.4 \pm 5.6$ & $29.9 \pm 3.1$ & 0.595 \\
LA dimension, mm & $33.7 \pm 3.5$ & $33.1 \pm 4.6$ & 0.386 \\
LVEF, \% & $64.3 \pm 5.1$ & $63.7 \pm 4.4$ & 0.573 \\
RV dimension, mm & $27.1 \pm 2.5$ & $27.4 \pm 2.6$ & 0.844 \\
PAB $(\mathrm{s}), \mathrm{mm} \mathrm{Hg}$ & $24.2 \pm 5.3$ & $23.4 \pm 5.5$ & 0.856 \\
DT, ms & $175.3 \pm 26.9$ & $172.4 \pm 27.2$ & 0.388 \\
IVRT, ms & $86.2 \pm 13.2$ & $83.4 \pm 14.5$ & 0.258 \\
E, m.s ${ }^{-1}$ & $0.55 \pm 0.19$ & $0.58 \pm 0.19$ & 0.563 \\
A, m $\cdot \mathrm{s}^{-1}$ & $0.49 \pm 0.14$ & $0.51 \pm 0.11$ & 0.422 \\
E/A ratio & $1.1 \pm 0.4$ & $1.1 \pm 0.3$ & 0.618 \\
CO, ml/min & $5,790 \pm 625$ & $7,986 \pm 744$ & $<0.001$ \\
\hline
\end{tabular}

IVS = Ventricular septal thickness; $\mathrm{PW}=$ posterior wall thickness; $L V E D D=$ left ventricular end-diastolic dimension; LVESD = left ventricular end-systolic dimension; LA = left atrium; $\mathrm{LVEF}=$ left ventricular ejection fraction; RV = right ventricular; $\mathrm{PAB}(\mathrm{s})=$ systolic pulmonary artery pressure; $\mathrm{DT}=$ deceleration time; IVRT = isovolumetric relaxation time; $\mathrm{CO}=$ cardiac output.

Table 3. LA volume measurements and mechanical function

\begin{tabular}{llll}
\hline & $\begin{array}{l}\text { Preeclampsia } \\
\text { group } \\
(\mathrm{n}=36)\end{array}$ & $\begin{array}{l}\text { Control } \\
\text { group } \\
(\mathrm{n}=34)\end{array}$ & p value \\
\hline $\mathrm{LA} \mathrm{Vmax,} \mathrm{ml} \cdot \mathrm{m}^{-2}$ & $33.4 \pm 6.7$ & $34.5 \pm 6.8$ & 0.343 \\
LA Vmin, $\mathrm{ml} \cdot \mathrm{m}^{-2}$ & $11.4 \pm 3.1$ & $12.1 \pm 3.4$ & 0.446 \\
$\mathrm{LA} \mathrm{Vp}, \mathrm{ml} \cdot \mathrm{m}^{-2}$ & $22.4 \pm 4.8$ & $21.8 \pm 5.4$ & 0.348 \\
$\mathrm{LAEF}, \%$ & $34.6 \pm 6.8$ & $34.4 \pm 7.1$ & 0.458 \\
LATEV $\mathrm{ml} \cdot \mathrm{m}^{-2}$ & $21.2 \pm 4.8$ & $22.5 \pm 5.1$ & 0.389 \\
LAAEF, \% & $0.33 \pm 0.11$ & $0.33 \pm 0.13$ & 0.959 \\
LAAEV, $\mathrm{ml} \cdot \mathrm{m}^{-2}$ & $8.8 \pm 3.4$ & $8.3 \pm 4.1$ & 0.585 \\
LAPEF, \% & $0.29 \pm 0.06$ & $0.30 \pm 0.10$ & 0.661 \\
LAPEV, $\mathrm{ml} \cdot \mathrm{m}^{-2}$ & $11.6 \pm 3.7$ & $11.2 \pm 4.4$ & 0.669 \\
\hline
\end{tabular}

LAEF = Left atrium ejection fraction; LATEV = left atrium total emptying volume; LAAEF = left atrium active emptying fraction; LAAEV = left atrium active emptying volume; LAPEF = left atrium passive emptying fraction; LAPEV = left atrium passive emptying volume.

sions, LV end-systolic dimensions, LV ejection fraction, LA, RV dimensions, or systolic pulmonary arterial pressure parameters, or such diastolic parameters as deceleration time, isovolumetric relaxation time, early diastolic
Table 4. Electrocardiographic and tissue Doppler echocardiographic findings

\begin{tabular}{lclr}
\hline & $\begin{array}{l}\text { Preeclampsia } \\
\text { group } \\
(\mathrm{n}=36)\end{array}$ & $\begin{array}{l}\text { Control } \\
\text { group } \\
(\mathrm{n}=34)\end{array}$ & p value \\
\hline PA lateral, ms & $74.6 \pm 8.1$ & $62.3 \pm 5.3$ & $<0.001$ \\
PA septal, ms & $59.7 \pm 5.3$ & $56.2 \pm 4.9$ & 0.005 \\
PA tricuspid, ms & $49.2 \pm 4.6$ & $48.9 \pm 4.8$ & 0.836 \\
IA-EMD, ms & $25.4 \pm 4.6$ & $13.2 \pm 3.9$ & $<0.001$ \\
IRight-EMD, ms & $10.5 \pm 1.9$ & $7.1 \pm 1.2$ & $<0.001$ \\
Pmax, ms & $104.5 \pm 11.2$ & $97.5 \pm 10.2$ & 0.051 \\
Pmin, ms & $61.3 \pm 7.4$ & $57.1 \pm 7.9$ & 0.011 \\
PWD, ms & $43.1 \pm 9.1$ & $37.6 \pm 7.9$ & 0.008 \\
\hline
\end{tabular}

$\mathrm{PA}=$ Time interval from the onset of the P-wave on the surface ECG to the beginning of the late diastolic wave (A wave); IA$\mathrm{EMD}=$ interatrial electromechanical delay; IRight-EMD = intraright electromechanical delay.

flow (E), atrial contraction signal (A) values, and the E/A ratio between groups ( $p>0.05)$ (table 2$)$.

The LA volume indices are shown in table 3 . There were no significant differences in LA diameter, LAVmax, LAVmin, LAVp, LA passive emptying volume, LA passive emptying fraction, LA active emptying volume, LA active emptying fraction, conduit volume, LA total emptying volume, or LA total emptying fraction between the preeclampsia and control groups ( $p>0.05)$. Atrial electromechanical coupling parameters at different sites measured via tissue Doppler imaging are shown in table 4. PA lateral and PA septal durations were significantly longer in the preeclampsia group than in the control group [74.6 \pm 8.1 vs. $62.3 .4 \pm 5.3 \mathrm{~ms}(\mathrm{p}<0.001)$ and $59.7 \pm 5.3$ vs. $56.2 \pm$ $4.9 \mathrm{~ms}$ ( $\mathrm{p}=0.005)$, respectively]. There was no significant difference in PA tricuspid duration between the preeclampsia and control groups ( $49.2 \pm 4.6$ vs. $48.9 \pm 4.8 \mathrm{~ms}$; $\mathrm{p}=0.836$ ). Increased interatrial (PA lateral - PA tricuspid) and intra-atrial (PA septal - PA tricuspid) EMD were observed in the preeclampsia group [ $25.4 \pm 4.6$ vs. $13.2 \pm 3.9$ $\mathrm{ms}$ and $10.5 \pm 1.9$ vs. $7.1 \pm 1.2 \mathrm{~ms}(\mathrm{p}<0.001)$, respectively].

$\mathrm{P}$-wave measurements are presented in table 4. Pmax did not differ significantly between the groups (104.5 \pm 11.2 vs. $97.5 \pm 10.2 \mathrm{~ms} ; \mathrm{p}=0.051)$. Pmin and PWD were significantly higher in the preeclampsia group than in the control group [61.3 \pm 7.4 vs. $57.1 \pm 7.9 \mathrm{~ms}(\mathrm{p}=0.011)$ and $43.1 \pm 9.1$ vs. $37.6 \pm 7.9 \mathrm{~ms}(\mathrm{p}=0.008)$, respectively]. There was a significant correlation between PWD and interatrial EMD and intra-atrial EMD $[\mathrm{r}=0.46(\mathrm{p}<0.001)$ and $r=0.39(p<0.001)$, respectively; fig. 1]. 
Fig. 1. A positive correlation was detected between interatrial/intra-atrial EMD and PWD.

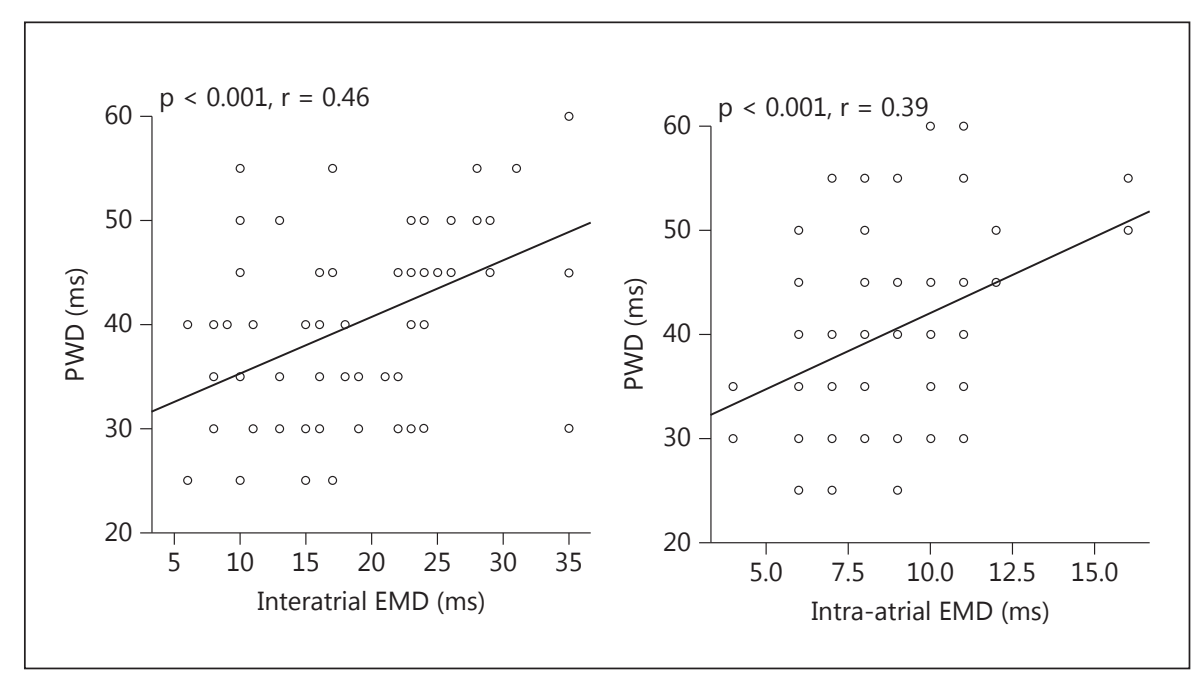

\section{Discussion}

In this study, the PWD time and the atrial EMD time were significantly prolonged in patients with preeclampsia compared to those without preeclampsia; there was no statistically significant difference in LA mechanical function between the 2 groups, and PWD was correlated with the atrial electromechanical conduction interval.

$\mathrm{AF}$ is among the most important causes of stroke, and its incidence is increased in hypertensive patients due to the development of LV diastolic dysfunction in cases of arterial hypertension; fibrosis occurs in the LA and LV [17]. Prolongation of intra-atrial and interatrial EMD and inhomogeneous propagation of sinus impulses are wellknown electrophysiological characteristics of atria prone to fibrillation $[5,6,9,18,19]$. PWD is associated with inhomogeneous and interrupted conduction of sinus impulses, both intra-atrially and interatrially [19]. Our hypothesis is based on the fact that electrical and structural LA changes that occur in chronic arterial hypertension might also occur in cases of acute hypertension - including preeclampsia - and might play a role in altering the atrial EMD time. A prolonged atrial conduction time and increased PWD can occur due to many physiopathological mechanisms that develop on a chronic basis. However, this association is not clear in the case of acute hypertension, including preeclampsia. One such mechanism could be the fact that hypertension in preeclampsia may lead to enhanced atrial stretch, even in the acute phase. Even though it does not affect LA mechanical function like chronic atrial stretching does, it may influence electrical functions. Another possible mechanism might be increased sympathetic activation. Studies have reported prolongation of PWD and the conduction time with increased sympathetic activity [20]. Another mechanism might be increased angiotensin II due to activation of the renin-angiotensin system. Clinical and experimental studies have shown that angiotensin II could be directly involved in atrial electrical remodeling [21]. Another mechanism may be associated with the inflammatory process that occurs in early preeclampsia [22]. Therefore, the extended PWD and AEMG times observed in preeclampsia patients may result from the electrical remodeling caused by acute hypertension on the atrium through the above-mentioned mechanisms.

In the present study, there was no significant difference in LA mechanical function between the preeclampsia and control groups. Similarly, the nonstatistically significant difference in LA mechanical function between the preeclampsia and control groups confirmed the previous finding [23] that LA function is not affected by short-term pressure overload. A plausible explanation could be that LA function is influenced by long-term pressure overload [24], but not by short-term pressure overload, because of the fact that short-term hypertension does not affect LA mechanical function.

P-wave duration and PWD are the most important ECG markers used to assess the risk of atrial arrhythmia, and they have also been shown to be predictive of the development of AF [11]. Prolonged PWD is observed in many clinical conditions, including metabolic syndrome, obstructive sleep apnea, congestive heart failure, rheumatoid arthritis, and psoriasis, and this is associated with further AF development [7, 25-27]. Dilaveris et al. [28] reported that PWD 
is prolonged in hypertensive patients with a history of AF and that prolonged PWD might be a predictor of paroxysmal AF. Ermis et al. [29] observed that PWD was prolonged in dipper and nondipper hypertensive patients, compared to controls, and that PWD was significantly prolonged in nondippers. Emiroglu et al. [4] showed that patients with hypertension had prolonged PWD. The prolonged PWD observed in the present study is consistent with the aforementioned studies. Prolonged PWD probably arises from the effect of physiopathological mechanisms caused by arterial hypertension. Hence, a close association between PWD and sympathetic activity had been shown in earlier studies [20], but the literature does not include any studies on PWD in preeclampsia patients.

Interatrial and intra-atrial EMD and the nonhomogeneous spread of sinus stimulation are well-known electrophysiological characteristics of atria that are prone to AF. Atrial EMD can be measured using invasive and noninvasive methods. Tissue Doppler imaging, along with advanced echocardiographic techniques, is an alternative method $[5,6]$. Unlike the LA volume, the atrial conduction time can indicate both structural and electrical remodeling in the atria. In the present study, atrial EMD was significantly prolonged in the preeclampsia group, and a correlation between PWD and both interatrial and intra-atrial conduction delay was observed. Similarly, previous studies have shown that atrial EMD is significantly prolonged in paroxysmal AF patients $[5,6]$. Atrial EMD is prolonged in various groups of patients, including those with essential hypertension, prehypertension, and nondipper hypertension, and there is a correlation between PWD and interatrial EMD [3, 4, 29].

On the basis of the present findings, we speculate that prolonged intra-atrial and interatrial EMD might be an early form of subclinical cardiac involvement in preeclampsia patients who do not have any clinical evi- dence of cardiovascular disease. Hence, the risk of new and/or recurrent AF might be high in preeclampsia patients.

The major limitations of the present study were its cross-sectional design, the lack of patient follow-up, and the small study population. Because the patients were not followed up for arrhythmic events, it is not known whether PWD and prolonged atrial EMD were predictors of atrial arrhythmias. Another limitation was that our patient group had placental preeclampsia (cardiac changes may start in the first trimester in this type of preeclampsia) and the patients were not followed up during the first trimester. The other limitation was the use of a 12-lead ECG instead of a signal-averaged electrocardiogram to evaluate $\mathrm{P}$-wave duration. Long-term follow-up and large-scale prospective studies are needed to more clearly determine the predictive value of prolonged intra-atrial and interatrial EMD in patients with preeclampsia.

\section{Conclusion}

Prolonged intra-atrial and interatrial EMD and PWD were observed in preeclampsia patients compared to controls. These parameters, which are associated with an increased risk of $\mathrm{AF}$, might be predictors of the risk of $\mathrm{AF}$ in preeclampsia patients. A more thorough and earlier assessment of preeclampsia patients in cardiac terms is important in order to avoid subclinical cardiac damage in these patients.

\section{Disclosure Statement}

The authors declare that they have no conflicts of interest.

\section{References}

1 Shennan AH, Redman C, Cooper C, et al: Are most maternal deaths from preeclampsia avoidable? Lancet 2012;379:1686-1687.

2 Drost JT, Maas AH, van Eyck J, et.al: Preeclampsia as a female-specific risk factor for chronic hypertension. Maturitas 2010;67: 321-326.

3 Sarıkaya S, Sahin S, Oztürk S, et al: Detection of atrial electrical and mechanical dysfunction in non-dipper pre-hypertensive subjects. Clin Exp Hypertens 2013;28:1-6.
4 Emiroglu MY, Bulut M, Sahin M, et al: Assessment of atrial conduction time in patients with essential hypertension. J Electrocardiol 2011;44:251-256.

5 Cui QQ, Zhang W, Wang H, et al: Assessment of atrial electromechanical coupling and influential factors in nonrheumatic paroxysmal atrial fibrillation. Clin Cardiol 2008;31:74-78.

6 Omi W, Nagai H, Takamura M, et al: Doppler tissue analysis of atrial electromechanical coupling in paroxysmal atrial fibrillation. J Am Soc Echocardiogr 2005; 18:39-44.
7 Dilaveris EJ, Gialafos S, Sideris K, et al: Simple electrocardiographic markers for the prediction of paroxysmal idiopathic atrial fibrillation. Am Heart J 1998:135:733-738.

8 Centurion OA: Clinical implications of the $\mathrm{P}$ wave duration and dispersion: relationship between atrial conduction defects and abnormally prolonged and fractionated atrial endocardial electrograms. Int J Cardiol 2009;134: 6-8. 
-9 Ozer N, Yavuz B, Can I, et al: Doppler tissue evaluation of intra-atrial and interatrial electromechanical delay and comparison with $\mathrm{P}$ wave dispersion in patients with mitral stenosis. J Am Soc Echocardiogr 2005;18:945-948.

10 Davey DA, MacGillivray I: The classification and definition of the hypertensive disorders of pregnancy. Am J Obstet Gynecol 1988;158: 892-898.

11 Michelucci A, Bagliani G, Colella A, et al: P wave assessment: state of the art update. Card Electrophysiol Rev 2002;6:215-220.

12 Quinones MA, Otto CM, Stoddard M, et al: Recommendations for quantification of Doppler echocardiography: a report from the Doppler Quantification Task Force of the Nomenclature and Standards Committee of the American Society of Echocardiography. J Am Soc Echocardiogr 2002;15:167-184.

13 Lang RM, Bierig M, Devereux RB, et al: Recommendations for chamber quantification: a report from the American Society of Echocardiography's Guidelines and Standards Committee and the Chamber Quantification Writing Group, developed in conjunction with the European Association of Echocardiography, a branch of the European Society of Cardiology. J Am Soc Echocardiogr 2005;18:1440 1463.

14 Aydin M, Ozeren A, Bilge M, et al: Effects of dipper and non-dipper status of essential hypertension on left atrial mechanical functions. Int J Cardiol 2004;96:419-424.
15 De Vos CB, Weijs B, Crijns HJ, et al: Atrial tissue Doppler imaging for prediction of newonset atrial fibrillation. Heart 2009;95:835840.

16 Dabrowska-Kugacka A, Lewicka-Nowak E, Rucinski P, et al: Atrial electromechanical sequence and contraction synchrony during single-and multisite atrial pacing in patients with brady-tachycardia syndrome. Pacing Clin Electrophysiol 2009;32:591-603.

17 Fuster V, Ryden LE, Asinger RW: ACC/ AHA/ESC guidelines for the management of patients with atrial fibrillation - executive summary: a report of the American College of Cardiology/American Heart Association Task Force on Practice Guidelines and the European Society of Cardiology Committee for Practice Guidelines and Policy Conferences. Circulation 2001;104:2118-2150.

18 Dilaveris P, Gialafos EJ, Sideris S, et al: Simple electrocardiographic markers for the predic tion of paroxysmal idiopathic atrial fibrillation. Am Heart J 1998;135:733-738.

19 Aytemir K, Ozer N, Atalar E, et al: P wave dispersion on 12-lead electrocardiography in patients with paroxysmal atrial fibrillation. Pacing Clin Electrophysiol 2000;23:1109-1112.

20 Tükek T, Akkaya V, Demirel S, et al: Effect of Valsalva maneuver on surface electrocardiographic $\mathrm{P}$-wave dispersion in paroxysmal atrial fibrillation. Am J Cardiol 2000;85:896-899.

21 Lombardi F, Terranova P: Renin-angiotensin system block and atrial fibrillation. Curr Med Chem 2005;12:1331-1337.
22 Oylumlu M, Dogan A, Ozer O, et al: Effects of lying position on $\mathrm{P}$-wave dispersion in patients with heart failure. Med Princ Pract 2014;23:556-560.

3 Ingec M, Yilmaz M, Gundogdu F: Left atrial mechanical functions in pre-eclampsia. J Obstet Gynaecol Res 2005;31:535-539.

24 Dernellis JM, Vyssoulis GP, Zacharoulis AA, et al: Effects of antihypertensive therapy on left atrial function. J Hum Hypertens 1996;10: 789-794.

25 Yagmur J, Yetkin O, Cansel M, et al: Assessment of atrial electromechanical delay and influential factors in patients with obstructive sleep apnea. Sleep Breath 2012;16:83-88.

26 Yasar AS, Bilen E, Bilge M, et al: P-wave duration and dispersion in patients with metabolic syndrome. Pacing Clin Electrophysiol 2009;32:1168-1172.

27 Raghupathy R: Cytokines as key players in the pathophysiology of preeclampsia. Med Princ Pract 2013;22:8-19.

28 Dilaveris P, Gialafos EJ, Chrissos D, et al: Detection of hypertensive patients at risk for paroxysmal atrial fibrillation during sinus rhythm by computer-assisted $\mathrm{P}$ wave analysis. J Hypertens 1999;17:1463-1470.

29 Ermis N, Acikgoz N, Cuglan B, et al: Comparison of atrial electromechanical coupling interval and $\mathrm{P}$-wave dispersion in non-dipper versus dipper hypertensive subjects. Blood Press 2011;20:60-66. 